\title{
Microbial sequencing to improve individual and population health
}

\author{
Sharon J Peacock ${ }^{1,2^{*}}$ and George M Weinstock ${ }^{3}$
}

\begin{abstract}
Editorial summary
Recent advances in sequencing technologies are changing the face of infectious disease investigation and control. Personalized anti-infective therapies and surveillance of emergent pathogen outbreaks are just two examples of the potential benefits of merging the fields of genomics and infectious diseases.
\end{abstract}

\section{Editorial}

This Genome Biology and Genome Medicine collaborative special issue on the genomics of infectious diseases is very timely. Vaccination, access to clean water, and antimicrobial drugs have all changed the relationship between humans and pathogens, resulting in a marked increase in life expectancy. Yet, infectious diseases continue to take their toll on human health worldwide, and events such as the recent Ebola outbreak in West Africa serve as a sharp reminder of how fragile any success is in the control of pathogens. A more insidious but pervasive threat to human health is the emergence and dissemination of antimicrobial resistance among numerous pathogens, paralleled by a decline in antimicrobial drug discovery. Advances in sequencing technologies have resulted in the availability of instruments that can be operated in a clinical environment, together with highthroughput platforms that can be used to define pathogens at the population level. These technologies have numerous potential applications for the control of infectious diseases.

Sequencing will bring improvements in the detection and control of outbreaks associated with multidrugresistant and other pathogens in hospitals and the community [1]. Confirmation of an outbreak could lead to earlier implementation of interventions that bring the outbreak to a close [2]. Conversely, excluding an outbreak

\footnotetext{
* Correspondence: sjp97@medschl.cam.ac.uk

${ }^{1}$ Department of Medicine, University of Cambridge, Box 157 Addenbrooke's

Hospital, Hills Road, Cambridge CB2 OQQ, UK

${ }^{2}$ The Wellcome Trust Sanger Institute, Wellcome Trust Genome Campus, Hinxton, Cambridge CB10 1SA, UK

Full list of author information is available at the end of the article
}

with confidence will reduce unnecessary infection control interventions [3]. Pathogen sequencing will be used to tailor individual patient prescribing. Capillary sequencing of the human immunodeficiency virus (HIV) is already used to guide the treatment of patients who are HIV positive, but newer sequencing technologies will bring the added benefit of detecting resistant variants present as a minority of the HIV population in a given individual. In tuberculosis (TB), sequencing technologies will be used to predict antimicrobial resistance of the causative agent, Mycobacterium tuberculosis [4]. This will bring the greatest benefit to patients with multidrug-resistant and extensively drug-resistant TB (against which first- and second-line drugs are not effective), because conventional testing of second-line drugs is lengthy. Accurate prescribing could lead to more rapid resolution of infection and reduced risk of onward transmission. Genome sequencing also defines transmission of $M$. tuberculosis between individuals with greater resolution and certainty than was previously possible [5].

Passive surveillance using sequence data generated for clinical use would provide an overview of the emergence and spread of antimicrobial resistance. Active genomic surveillance of key human pathogens would provide an early warning system for outbreaks, inform vaccine strategies through tracking of vaccine escape, and detect the emergence of new clones that harbor known or novel virulence determinants. Sequencing is being used to identify reservoirs of antimicrobial-resistance genes in hospitals, other healthcare facilities, the community, and livestock farming, as well as common transmission pathways between them. Finding pinch-points to stop transmission between reservoirs could limit the dissemination of antimicrobial resistance. Sequencing also provides insights into the emergence of infectious diseases. For example, reconstruction of the early dynamics of the HIV pandemic using sequence data and statistical approaches identified Kinshasa in the 1920 s as the focus of early transmission and the source of pre-1960 pandemic viruses elsewhere [6]. Sequencing of the more recently 
emerged Middle East respiratory syndrome coronavirus and comparison of sequence data for isolates from humans and dromedary camels has been cited as evidence for the role of camels as a reservoir [7].

Sequencing also has a role in drug discovery pathways, the laboratory evaluation of lead compounds, and the clinical phases of drug evaluation. For example, in 2005, in the first published use of 454 pyrosequencing, the F0 subunit of ATP synthase was identified as the target of bedaquiline [8]. Bedaquiline subsequently became the first representative of the only novel class of anti-TB agents to be approved in 40 years. Sequencing of $M$. tuberculosis during clinical trials can be used to distinguish exogenous re-infection from a relapse of the primary infection, which is crucial to assess the efficacy of study drugs. Sequencing technologies will also underpin clinical trials evaluating the effect of a therapeutic alteration of the microbiome in a range of conditions. The benefit derived from duodenal infusion of donor feces in patients with recurrent Clostridium difficile infection provides proof-of-principle for clinical utility [9]. Extending this to other diseases will need to be supported by detailed genomic analyses of the human microbiota, together with a better understanding of the interactions between the native or medically altered microbiome and host immunity.

Several challenges remain before microbial sequencing becomes routine for diagnostic and public health microbiology laboratories. A suite of software tools will be required to convert sequence data into a format that is relevant and useful for clinicians and infection control teams. New methods to handle and process everexpanding pathogen-specific microbial genome databases will also be needed, including global and region-specific listings of gene mutations associated with drug resistance. It is also essential that existing mechanisms for the development of standard operating procedures and accreditation of laboratory methods be applied to microbial sequencing. Working within a tightly controlled diagnostic laboratory will reduce errors (for example, through sample tracking) and allow data to be handled within an existing framework that protects patient confidentiality.

Further technological advances are also required to reduce the turnaround time between taking a clinical sample and generating sequence data. Refinements such as extracting DNA directly from a bacterial colony on a culture plate can reduce the processing time by up to a day [10]. However, the need to culture the sample to obtain a pure growth of bacteria from which to purify DNA prior to sequencing, rather than performing direct sequencing on the sample, means that timelines are still tied to bacteriology methods that were developed more than a hundred years ago. Regardless, the enthusiasm for direct sequencing of clinical samples should be tempered by the probable reality of doing so. Most samples sent to a diagnostic laboratory are currently reported out as 'no growth' or, through the use of selective culture media that target specific pathogens, 'no significant growth'. In a brave new world where all samples are sequenced as the primary method for pathogen detection, it may prove the case that the majority of samples will be sequence-positive. Re-defining what data can be disregarded and what might represent new and important findings will take at least a generation of microbiologists to resolve.

\section{Abbreviations}

HIV: Human immunodeficiency virus; TB: Tuberculosis.

\section{Competing interests}

The authors declare that they have no competing interests.

\section{Author details}

1Department of Medicine, University of Cambridge, Box 157 Addenbrooke's Hospital, Hills Road, Cambridge CB2 OQQ, UK. ${ }^{2}$ The Wellcome Trust Sanger Institute, Wellcome Trust Genome Campus, Hinxton, Cambridge CB10 1SA, UK. ${ }^{3}$ The Jackson Laboratory for Genomic Medicine, At the University of Connecticut Health Center, Administrative Services Building, 263 Farmington Ave, Farmington, CT 06030, USA.

Published online: 19 November 2014

\section{References}

1. Köser CU, Ellington MJ, Cartwright EJP, Gillespie SH, Brown NM, Farrington M, Holden MT, Dougan G, Bentley SD, Parkhill J, Peacock SJ: Routine use of microbial whole genome sequencing in diagnostic and public health microbiology. PLoS Pathogens 2012, 8:e1002824.

2. Harris SR, Cartwright EJ, Török ME, Holden MT, Brown NM, Ogilvy-Stuart AL, Ellington MJ, Quail MA, Bentley SD, Parkhill J, Peacock SJ: Whole-genome sequencing for analysis of an outbreak of meticillin-resistant Staphylococcus aureus: a descriptive study. Lancet Infect Dis 2013, 13:130-136.

3. Török ME, Harris SR, Cartwright EJ, Raven KE, Brown NM, Allison ME, Greaves D, Quail MA, Limmathurotsakul D, Holden MT, Parkhill J, Peacock SJ: Zero tolerance for healthcare-associated MRSA bacteraemia: is it realistic? $J$ Antimicrob Chemother 2014, 69:2238-2245.

4. Köser CU, Bryant JM, Becq J, Török ME, Ellington MJ, Marti-Renom MA, Carmichael AJ, Parkhill J, Smith GP, Peacock SJ: Whole-genome sequencing for rapid susceptibility testing of M. tuberculosis. N Engl J Med 2013, 369:290-292.

5. Gardy JL, Johnston JC, Ho Sui SJ, Cook VJ, Shah L, Brodkin E, Rempel S, Moore R, Zhao Y, Holt R, Varhol R, Birol I, Lem M, Sharma MK, Elwood K, Jones SJ, Brinkman FS, Brunham RC, Tang P: Whole-genome sequencing and social-network analysis of a tuberculosis outbreak. $N$ Engl J Med 2011, 364:730-739.

6. Faria NR, Rambaut A, Suchard MA, Baele G, Bedford T, Ward MJ, Tatem AJ, Sousa JD, Arinaminpathy N, Pépin J, Posada D, Peeters M, Pybus OG, Lemey P: HIV epidemiology. The early spread and epidemic ignition of HIV-1 in human populations. Science 2014, 346:56-61.

7. Haagmans BL, Al Dhahiry SH, Reusken CB, Raj VS, Galiano M, Myers R, Godeke GJ, Jonges M, Farag E, Diab A, Ghobashy H, Alhajri F, Al-Thani M, Al-Marri SA, Al Romaihi HE, Al Khal A, Bermingham A, Osterhaus AD, AlHajri MM, Koopmans MP: Middle East respiratory syndrome coronavirus in dromedary camels: an outbreak investigation. Lancet Infect Dis 2014, 14:140-145.

8. Andries K, Verhasselt P, Guillemont J, Göhlmann HW, Neefs JM, Winkler H, Van Gestel J, Timmerman P, Zhu M, Lee E, Williams P, de Chaffoy D, Huitric E, Hoffner S, Cambau E, Truffot-Pernot C, Lounis N, Jarlier V: A diarylquinoline drug active on the ATP synthase of Mycobacterium tuberculosis. Science 2005, 307:223-227.

9. van Nood E, Vrieze A, Nieuwdorp M, Fuentes S, Zoetendal EG, de Vos WM, Visser CE, Kuijper EJ, Bartelsman JF, Tijssen JG, Speelman P, Dijkgraaf MG, 
Keller JJ: Duodenal infusion of donor feces for recurrent Clostridium difficile. N Engl I Med 2013, 368:407-415.

10. Köser CU, Fraser LJ, loannou A, Becq J, Ellington MJ, Holden MT, Reuter S, Török ME, Bentley SD, Parkhill J, Gormley NA, Smith GP, Peacock SJ: Rapid single-colony whole-genome sequencing of bacterial pathogens. J Antimicrob Chemother 2014, 69:1275-1281.

doi:10.1186/s13073-014-0103-5

Cite this article as: Peacock and Weinstock: Microbial sequencing to

improve individual and population health. Genome Medicine 2014 6:103. 